\title{
Inobservância à lei de acesso à informação por órgãos públicos na disponibilização de ferramenta de transparência pública ${ }^{1}$
}

\section{Non-observance to the access to information law by public entities in providing public transparency tool}

\author{
Malhadas, Maíra Regina' \\ 1 Universidade Federal do Rio de Janeiro, Av. Athos da Silveira Ramos, 149, \\ Cidade Universitária, Rio de Janeiro, Brasil, maira.malhadas@poli.ufrj.br
}

\begin{abstract}
RESUMO
A Lei de Acesso à Informação busca aumentar a transparência na administração pública, facilitando, entre outros pontos, a participação da população nos processos decisórios. Para isso, além das informações apresentados de forma ativa, a lei determina aos entes públicos a disponibilização de meios online que viabilizem a solicitação de informações não confidenciais pelos cidadãos. Este trabalho, que integra pesquisa realizada para produção de dissertação de mestrado, avalia a adequação de agentes públicos à oferta e ao uso desses instrumentos, através da solicitação eletrônica de documento obrigatório em processos de parcerias público-privadas. Dos órgãos pesquisados, 12\% não disponibilizam meio eletrônico para realizar a solicitação, e somente $35 \%$ apresentam a possibilidade de interposição de recurso. Verificou-se que a lei não é cumprida em maior ou menor grau nos aspectos observados, e a análise indica que o despreparo dos órgãos e a ausência de um órgão supervisor em nível subnacional estão entre os principais obstáculos ao cumprimento da lei. Sugere-se ainda uma melhor regulamentação da lei para garantir o atendimento adequado e um meio efetivo para participação dos cidadãos.
\end{abstract}

Palavras Chave: Transparência Passiva, e-SIC, Serviço de Informação ao Cidadão, Governança.

\section{ABSTRACT}

The Brazilian access to information law seeks to increase transparency in public administration, facilitating, among other points, the participation of the population in decision-making processes. For this, in addition to the information presented in an active way, the law determines the need to public entities to provide online instruments allowing any citizen to request access to non-confidential information. This work, which integrates research carried out to produce a master's thesis, evaluates the adequacy of public entities to these instruments by requesting an obligate document in the process of public-private partnerships. Of the entities surveyed, $12 \%$ do not provide electronic means to make the request, and only $35 \%$

\footnotetext{
${ }^{1}$ MALHADAS, Maíra Regina. Inobservância à Lei de Acesso à Informação por órgãos públicos na disponibilização de ferramenta de transparência pública. In: II SIMPÓSIO NACIONAL DE GESTÃO E ENGENHARIA URBANA: SINGEURB, 2019, São Paulo. Anais... Porto Alegre: ANTAC, 2019.
} 
present the possibility of lodging an appeal. The law is not fulfilled to a greater or lesser extent in the observed aspects, and the analysis indicates that the lack of preparation of the entities and the absence of a supervisory body at the subnational level are among the main obstacles to compliance with the law. Better regulation of the law is also suggested to ensure effective means for citizen participation.

Keywords: Passive Transparency, Citizen Information Service, Governance.

\section{INTRODUÇÃO}

A transparência dos atos públicos ganhou notoriedade no Brasil nos últimos anos, em função dos sucessivos escândalos relacionados à corrupção e mau uso do dinheiro público. Um dos principais instrumentos criados para aumentar a transparência na gestão pública é a Lei Federal $n^{\circ}$ 12.527/11 (Lei de Acesso à Informação - LAl), que regulamenta o acesso à informação previsto no Inciso XXXIII do Art. $5^{\circ}$ da Constituição Federal (BRASIL, 2017). A LAI busca contribuir com a eficiência na gestão pública, o combate à corrupção e a participação cidadã na gestão pública (ANGÉLICO; TEIXEIRA, 2012). No entanto, a simples existência da LAI não faz um governo transparente, é necessário que sua implementação seja eficiente, tornando as informações não somente acessíveis ao cidadão de forma completa e tempestiva, como também passíveis de verificação (MICHENER; BERSCH, 2013). A pouca divulgação da LAl e de seus instrumentos, em conjunto com questões socioculturais, como o pouco interesse da sociedade pela gestão pública e a baixa confiança nos instrumentos de regulação do Estado, podem impactar no atingimento dessas metas e culminar na existência de uma lei que não resulta em ganhos reais para a sociedade.

A LAl institui obrigações relativas à transparência ativa, que trata das informações que devem ser publicadas espontaneamente pelos entes públicos, e à passiva, que trata das informações que são disponibilizadas mediante solicitação. Para receber essas solicitações, a LAI determina que os órgãos públicos criem um serviço de informação ao cidadão (SIC). É obrigatório ainda que seja oferecida forma de realizar a solicitação por meio do sítio oficial de cada órgão na internet (BRASIL, 2011). Com o intuito de permitir uma melhor adaptação às realidades locais, a lei delega aos estados e municípios a regulamentação da implantação e operacionalização do serviço de informação. Na prática, no entanto, isso resulta na indefinição de unidades específicas para os atendimentos ou meios exclusivos para o recebimento das solicitações em diversos órgãos, o que diminui o grau de transparência e reduz pela metade a probabilidade de receber uma resposta quando comparado a situações em que o órgão indica um meio eletrônico específico para receber as solicitações de informações (MICHENER; CONTRERAS; NISKIER, 2018).

A LAl e as ferramentas para sua implementação são recentes, e ainda são poucos os estudos que avaliam sua efetividade, resultando em uma lacuna no entendimento sobre a administração pública e sua realidade (MICHENER; CONTRERAS; NISKIER, 2018;RAUPP, 2016). Os poucos estudos existentes indicam que há ainda alto grau de deficiência na divulgação das informações obrigatórias, com um grande caminho a ser percorrido para que seja cumprida a diretriz da LAI de que a transparência na gestão pública seja a regra (BAIRRAL; SILVA; ALVES, 2015). Para se avançar nessas questões, faz-se necessário um maior conhecimento sobre a realidade dos órgãos públicos no atendimento à LAl, com análises dos pontos que dificultam o acesso à informação e de exemplos positivos que possam ser replicados.

O presente trabalho avalia a disponibilização de meio eletrônico para realização de solicitações de acesso à informação em órgãos públicos.

\section{MÉTODO}

O universo de pesquisa foi delimitado a todos os entes públicos contratantes de parcerias público- privadas (PPP) assinadas no Brasil até janeiro de 2018, conforme levantamento realizado no site da RadarPPP (RADAR PPP, 2018). Entre fevereiro e maio de 2018 foi verificado 
o atendimento ao parágrafo $2^{\circ}$ do artigo 10 da LAl, que institui a obrigatoriedade de disponibilização de meio eletrônico para solicitação da informação (e-SIC).

A localização do e-SIC de cada órgão se deu por meio de busca de link para o e-SIC no portal da transparência ou na página inicial do sítio do órgão. Nos entes que não possuem eSIC, buscou-se a existência de ouvidoria, links do tipo "Fale Conosco" ou mesmo e-mail disponibilizado para contato, de forma a ser possível realizar a solicitação do estudo obrigatório que demonstra a conveniência e oportunidade da contratação da PPP. Nos casos em que o pedido não foi atendido na primeira resposta ou em que o prazo foi ultrapassado, verificou-se a possibilidade de recurso.

\section{RESULTADOS E DISCUSSÃO}

Os 103 contratos de PPP assinados no Brasil até janeiro de 2018 foram concedidos por 60 entes públicos (RADAR PPP, 2018). Dentre os 60, 41 são do poder executivo municipal, 14 do estadual e do Distrito Federal, quatro empresas públicas, sociedades de economia mista ou autarquias e uma instituição financeira federal.

A disponibilização de sistemas eletrônicos específicos para solicitação de informações por $70 \%$ dos entes pesquisados (Figura 1) é um indício de atenção às determinações da LAl, pois tende a garantir um melhor atendimento ao cidadão (MICHENER; CONTRERAS; NISKIER, 2018;MICHENER; MONCAU; VELASCO, 2014). Por outro lado, a não disponibilização de sistema e-SIC por $30 \%$ dos órgãos pesquisados demonstra que mesmo aspectos fundamentais da LAI não são atendidos em sua plenitude.

Figura 1 - Meio disponibilizado para realizar solicitação de informação.

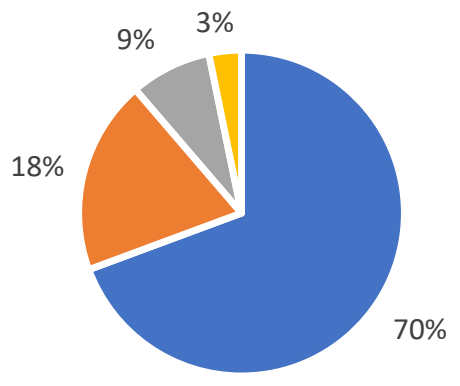

- e-SIC - centralizado na ouvidoria male conosco me-mail

Fonte: $O$ autor (2018)

Entre os entes que não disponibilizam e-SIC, é possível identificar algumas gradações de atendimento. Dos pesquisados, $12 \%$ não indicam um meio eletrônico para solicitações de informação, restando ao cidadão buscar no sítio da internet formulário ou e-mail para contato. Ao comparar com os entes que direcionam o cidadão ao serviço de ouvidoria para realizar suas solicitações, situação encontrada em $19 \%$ dos casos pesquisados, verifica-se que o primeiro grupo não atende o nível mais básico estipulado na LAI. Porém, ainda que a centralização na ouvidoria percebida no segundo grupo atenda de forma objetiva à obrigação de disponibilizar meio eletrônico para solicitação de informações, percebe-se que os sistemas não foram desenhados para atender às especificidades de prazos, trâmites e demais condições expostas na LAl, trazendo prejuízos ao atendimento e, consequentemente, à transparência.

Outro importante limitador percebido nos órgãos pesquisados é a impossibilidade de entrar com recurso. Em 20 órgãos não foi possível ou necessário verificar a possibilidade de interposição de recurso, pois o pedido foi atendido na primeira resposta ou não houve retorno no sistema. 
A Figura 2 mostra que, dos casos verificados, somente $35 \%$ dos órgãos apresentaram a possibilidade de recurso a partir da resposta oferecida. A impossibilidade de recurso verificada em $60 \%$ dos casos pode causar grande prejuízo ao solicitante, pois, segundo a LAl, o prazo para atendimento a recursos é de cinco dias, enquanto o prazo para atendimento a novas solicitações é de 20 dias, prorrogáveis por mais dez. Na prática, a inexistência dessa opção no sistema pode gerar 25 dias a mais para o atendimento, além da análise ser realizada pela mesma instância e sem guardar o histórico do pedido, diferentemente do que ocorre com os recursos. Alguns sistemas oferecem a opção de recurso somente quando o pedido é indeferido, situação verificada em $5 \%$ dos entes pesquisados. Ainda que essa opção se mostre melhor do que a ausência da possibilidade de recurso, apresenta os mesmos problemas nos casos em que a resposta é incorreta ou incompleta. Mesmo entre aqueles que permitem o envio de recurso, somente em quatro deles verificou-se essa possibilidade motivada por esgotamento do prazo de resposta, obrigatoriedade prevista na LAI. Essa ausência deixa o cidadão nas mãos do respondente, que pode demorar o tempo que quiser ou até mesmo não responder, sem existir uma forma imediata de acionar instâncias superiores para acusar o descumprimento dos prazos legais.

Figura 2 - Sistemas que permitem recurso.

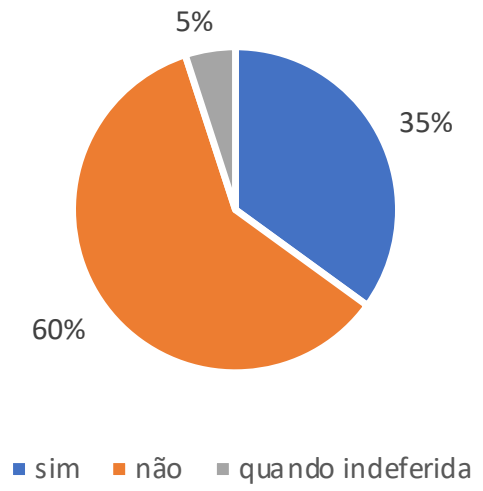

Fonte: O autor (2018)

Os sistemas apresentaram ainda problemas específicos, como por exemplo os que não informam ao cidadão a emissão de resposta. Ainda que não descumpra nenhum artigo da LAl, é uma forma de dificultar a busca de informações pelos cidadãos, pois exige que monitorem diariamente o sistema, sob pena de perder o prazo recursal por desconhecer a existência de resposta. Outro sistema pesquisado não registra a data da resposta do órgão, ferindo a transparência do processo e posterior aferição do cumprimento dos prazos. Esse mesmo órgão ainda desrespeita a LAl ao contabilizar os prazos recursais de forma cumulativa a partir do registro inicial da solicitação, quando o correto seria contar da data da resposta. Tal falha é minimizada pelo fato de que esse é um dos poucos sistemas que permite recurso por esgotamento do prazo para resposta, porém acaba repassando ao cidadão a obrigação de entrar com o recurso, sob pena de ficar impossibilitado de recorrer posteriormente. Outros órgãos possuem ainda sistemas que não permitem que o cidadão visualize o texto de sua solicitação, somente as respostas recebidas. Isso gera maior dificuldade na argumentação recursal, impedindo que sejam ressaltados pontos que já foram expostos e por vezes ignorados ou mal interpretados.

O universo pesquisado é composto em sua grande maioria por estados e municípios acima de 100 mil habitantes, portanto órgãos supostamente com estruturas maiores e boa disponibilidade de recursos tecnológicos quando comparados à média nacional. Considerando ainda que as PPP são processos complexos e que exigem um acompanhamento qualificado ao longo de todo o período da concessão, seria esperado que órgãos que atingiram maturidade para assinar esses contratos estariam entre os mais bem estruturados institucionalmente, incluindo fatores de transparência e atendimento ao cidadão. O alto índice de inadequação nesse grupo de estudo potencialmente melhor 
estruturado indica que o cumprimento à LAI pode se mostrar ainda menos efetivo quando analisado todo o cenário nacional.

Percebe-se que a falta de um órgão supervisor tende a diminuir a transparência dos atos públicos, já que a inexistência de um controle pode minimizar a preocupação dos servidores em atender ao disposto em lei e fornecer respostas ao cidadão. O aumento da fiscalização acerca do cumprimento da LAI por órgãos como o Ministério Público, ou a implantação de uma instituição central de controle, possivelmente supranacional, podem ser soluções para esse problema (MICHENER; CONTRERAS; NISKIER, 2018;MICHENER; MONCAU; VELASCO, 2014).

\section{CONSIDERAÇÕES FINAIS}

Com sete anos de LAl, ainda é alto o número dos órgãos estudados que não cumprem a lei na íntegra, e permanecem problemas e barreiras encontrados em estudos anteriores, como inexistência de plataformas específicas para solicitação de informações e sistemas que não apresentam possibilidade de recurso.

É preciso maior divulgação aos cidadãos e aos próprios servidores públicos sobre a LAl, suas diretrizes e ferramentas. Somente com a efetiva utilização dos sistemas e cobrança pelos cidadãos poderá ser alcançada a transparência pretendida.

É mandatório também mais clareza sobre a quem se deve recorrer no caso de o cidadão não obter as respostas de acordo com o estipulado na lei ou no caso de ausências de resposta, pois indefinições nesse sentido podem gerar descrédito no cumprimento da lei e reduzir sua aplicação.

Sugere-se estudar possibilidades de adequações na lei ou de emissão de regulamentação adicional à LAl sobre a forma como deve ser disponibilizado o serviço eletrônico de informação, além da definição sobre quais os órgãos independentes responsáveis pelo controle do atendimento. Essas medidas podem funcionar como motivadores tanto para os órgãos se estruturarem melhor para esse atendimento, quanto para os cidadãos buscarem mais esses importantes mecanismos de transparência e participação.

\section{REFERÊNCIAS}

ANGÉLICO, F.; TEIXEIRA, M. A. C. Acesso à Informação e Ação Comunicativa: Novo Trunfo para a Gestão Social. Desenvolvimento em Questão, [s.l.], v. 10, no 21, p. 7-27, 2012. ISSN: 2237-6453, DOI: https://doi.org/10.21527/2237-6453.2012.21.7-27.

BAIRRAL, M. A. da C.; SILVA, A. H. C. e; ALVES, F. J. dos S. Transparência no setor público: uma análise dos relatórios de gestão anuais de entidades públicas federais no ano de 2010. Revista de Administração Pública, [s.I.], v. 49, no 3, p. 643-675, 2015. ISSN: 0034-7612, DOI: 10.1590/0034-7612125158.

BRASIL. Lei no 12527. 2011. Disponível em: <http://www.planalto.gov.br/ccivil_03/_ato20112014/2011/lei/l12527.htm>. Acesso em: 22 fev.2018.

BRASIL. Constituição (1988). Brasília: Supremo Tribunal Federal, Secretaria de Documentação, 2017. 514 p. Disponível em:

<http://www.stf.jus.br/arquivo/cms/legislacaoConstituicao/anexo/CF.pdf>. Acesso em: 10 set. 2017.

MICHENER, G.; BERSCH, K. Identifying transparency. Information Polity, [s.I.], v. 18, no 3, p. 233242, 2013. ISBN: 15701255, ISSN: 15701255, DOI: 10.3233/IP-130299.

MICHENER, G.; CONTRERAS, E.; NISKIER, I. Da opacidade à transparência? Avaliando a Lei de Acesso à Informação no Brasil cinco anos depois. Revista de Administração Pública, [s.l.], v. 52, no 4, p. 610-629, 2018. DOI: 10.1590/0034-761220170289. 
MICHENER, G.; MONCAU, L. F. M.; VELASCO, R. Estado Brasileiro e Transparência: avaliando a aplicação da Lei de Acesso à Informação. Fundação Getúlio Vargas, [s.l.], p. 108, 2014.

RADAR PPP. sem título. 2018. Disponível em: <https://www.radarppp.com/painel-domercado/>. Acesso em: 13 jan.2018.

RAUPP, F. M. Realidade da transparência passiva em prefeituras dos maiores municípios brasileiros. Revista Contemporânea de Contabilidade, [s.I.], v. 13, n॰ 30, p. 34-52, 2016. ISSN: 2175-8069, DOI: 10.5007/2175-8069.2016v13n30p34. 